\title{
Trough colistin plasma level is an independent risk factor for nephrotoxicity: a prospective observational cohort study
}

\author{
Luisa Sorli ${ }^{1 *}$, Sonia Luque ${ }^{2}$, Santiago Grau ${ }^{2}$, Núria Berenguer ${ }^{2}$, Concepción Segura ${ }^{4}$, María Milagro Montero ${ }^{1}$, \\ Francisco Álvarez-Lerma ${ }^{3}$, Hernando Knobel ${ }^{1}$, Natividad Benito ${ }^{5,6}$ and Juan P Horcajada ${ }^{1}$
}

\begin{abstract}
Background: Data regarding the most efficacious and least toxic schedules for the use of colistin are scarce. The aim of this study was to determine the incidence and the potential risk factors of colistin-associated nephrotoxicity including colistin plasma levels.

Methods: A prospective observational cohort study was conducted for over one year in patients receiving intravenous colistin methanesulfonate sodium (CMS). Blood samples for colistin plasma levels were collected immediately before $\left(C_{\min }\right)$ and 30 minutes after CMS infusion $\left(C_{\text {max }}\right)$. Renal function was assessed at baseline, on day 7 and at the end of treatment (EOT). Severity of acute kidney injury (AKI) was defined by the RIFLE (risk, injury, failure, loss, and end-stage kidney disease) criteria.

Results: One hundred and two patients met the inclusion criteria. AKI related to CMS treatment on day 7 and at the end of treatment (EOT) was observed in 26 (25.5\%) and 50 (49.0\%) patients, respectively. At day 7, $\mathrm{C}_{\text {min }}(\mathrm{OR}, 4.63$ [2.33-9.20]; $P<0.001$ ) was the only independent predictor of AKI. At EOT, the Charlson score (OR 1.26 [1.01-1.57]; $P=0.036), C_{\min }(\mathrm{OR} 2.14$ [1.33-3.42]; $P=0.002)$, and concomitant treatment with $\geq 2$ nephrotoxic drugs (OR 2.61 [1.0-6.8]; $P=0.049$ ) were independent risk factors for AKI. When $C_{\min }$ was evaluated as a categorical variable, the breakpoints that better predicted AKI were $3.33 \mathrm{mg} / \mathrm{L}(\mathrm{P}<0.001)$ on day 7 and $2.42 \mathrm{mg} / \mathrm{L}(\mathrm{P}<0.001)$ at EOT.

Conclusions: When using the RIFLE criteria, colistin-related nephrotoxicity is observed in a high percentage of patients. $\mathrm{C}_{\text {min }}$ levels are predictive of AKI. Patients who receive intravenous colistin should be closely monitored and $\mathrm{C}_{\text {min }}$ might be a new useful tool to predict AKI.
\end{abstract}

Keywords: Colistin, Nephrotoxicity risk factors, RIFLE criteria, Colistin plasma levels

\section{Background}

Colistin is an old antibiotic that has been recently reintroduced in clinical practice because of the increase in the incidence of infections caused by multidrug resistant Gram-negative bacteria (MDR-GNB) and the retained antibacterial activity of colistin against MDR-GNB. However, data regarding its effectiveness and safety are scarce and controversial. For this reason, there is interest in determining the most effective and least toxic therapeutic schedule.

\footnotetext{
* Correspondence: LSorli@parcdesalutmar.cat

${ }^{1}$ Infectious Diseases Service, Parc de Salut Mar, Passeig Marítim 25-29,

E-08003 Barcelona, Spain

Full list of author information is available at the end of the article
}

Rates of nephrotoxicity in recent studies designed to assess this outcome have ranged from $6 \%$ to $14 \%$ in some and from $32 \%$ to $55 \%$ in others [1-4]. However, despite the large number of publications, different nephrotoxicity definitions, differences in dosing schedules, and a lack of control of risk factors for nephrotoxicity have complicated an understanding of the real clinical relevance of this adverse effect [5]. Furthermore, the nephrotoxicity of colistin has been assessed mainly in retrospective studies [6,7] that made it difficult to draw conclusions.

Risk factors for nephrotoxicity found in different studies included older age, pre-existing renal insufficiency, hypoalbuminemia, and concomitant use of non-steroidal

\section{Ciomed Central}


anti-inflammatory drugs (NSAIDs) or vancomycin [4]. Furthermore, some studies [7-11] have suggested that colistin-associated nephrotoxicity is related to the total cumulative dose and duration of therapy, whereas other studies have not shown this association [1,12]. However, the possible relationship between colistin plasma concentration and nephrotoxicity has not been previously assessed.

The aim of this study was to determine the incidence of and the risk factors for colistin-associated nephrotoxicity by using the RIFLE (risk, injury, failure, loss, and end-stage kidney disease) criteria and assessing the relationship between colistin plasma levels and nephrotoxicity.

\section{Methods}

This prospective observational study was performed at a 400-bed acute-care university hospital in Barcelona, Spain. A pharmacy-generated alarm system was used to identify patients on CMS treatment for therapy of infections caused by MDR-GNB. From January 2010 to June 2011 , patients ( $>18$ years) were included if they had received colistin methanesulfonate sodium (CMS) for at least 4 days. Patients were excluded if they were receiving renal replacement therapy prior to the initiation of CMS.

The ethical committee of the hospital (Comite Étic de Investigació Clínica del Parc de Salut MAR) approved the study. Informed consent was obtained from all participating patients or their legal representatives.

CMS for injection was used and dosed in millions of international units (IU) throughout the study. The drug was administered intravenously in $100 \mathrm{~mL}$ normal saline over 30 minutes in the commercially available colistimethate formulation for injection (GES Genéricos Españoles ${ }^{\circ}$ ), with each vial containing $80 \mathrm{mg}$ CMS (equivalent to 1 million international units of CMS). Dose selection was based on the individual criteria of the responsible clinicians, who were not aware that this study was being performed. Although there were some dose adjustments based on baseline renal function, common colistin doses ranged from 1 to 3 million international units (IU) every 8 hours (3-9 million IU daily). Dose adjustments were made according to the package insert's recommended dosing as follows: GFR $\geq 76 \mathrm{~mL} /$ $\min / 1.73 \mathrm{~m}^{2}, 4-6$ million IU daily in three doses; GFR 40 to $75 \mathrm{~mL} / \mathrm{min} / 1.73 \mathrm{~m}^{2}, 2-3$ million IU daily in 2 doses; GFR 25 to $40 \mathrm{~mL} / \mathrm{min} / 1.73 \mathrm{~m}^{2}, 1.5-2$ million IU daily divided in 1 or 2 doses and; GFR $<25 \mathrm{~mL} / \mathrm{min} /$ $1.73 \mathrm{~m}^{2}, 0.6-1$ million of IU daily every 36 hours.

Serum creatinine level and estimated glomerular filtration rate (GFR) were recorded at baseline, on day 7 and at the end of treatment (EOT). We chose these set points because blood tests are done routinely for all inpatients at least once a week and at the end of treatment. The abbreviated Modification of Diet in the Renal Disease Equation (MDRD-4) [13] was used to calculate GFR. Chronic kidney disease (CKD) at baseline was considered if GFR was $<60 \mathrm{~mL} / \mathrm{min} / 1.73 \mathrm{~m}^{2}$ for $\geq 3$ months. Patients with increased creatinine $(>1.4 \mathrm{mg} / \mathrm{dL})$ or GFR $<90 \mathrm{~mL} / \mathrm{min} / 1.73 \mathrm{~m}^{2}$ at admission and no prior data regarding chronicity were considered as having acute renal failure due to any cause. The RIFLE criteria (risk, injury, failure, loss, and end-stage kidney disease), estimated with exclusion of the urinary output criterion, were used for detection and stratification of AKI [14] (Table 1). AKI during CMS treatment was defined as a 1.5 -fold or more increase in serum creatinine and/or a decrease in the GFR of $25 \%$ or more. These criteria needed to be fulfilled for at least 2 consecutive determinations 24 hours apart, after $\geq 4$ days of CMS therapy. Patients who developed AKI were followed up for a period of 30 days after the end of CMS treatment to evaluate the reversibility of this toxicity. Patients who died or had no data during this period were excluded from this analysis.

Data on demographic characteristics including age, gender, body weight, size, and body mass index were collected. Data on the indication for CMS, the administration schedule, the daily CMS dose recorded as millions of IU, the total cumulative CMS dose (millions of IU), and the duration of treatment were collected. Other data recorded included the presence of CKD at baseline, the Charlson score [15], the severity of disease at the time of the first CMS dose stratified according to the Acute Physiology and the Chronic Health Evaluation (APACHE) II [16]. The concomitant use of aminoglycosides, vancomycin, angiotensin II receptor blockers, angiotensin-converting enzyme inhibitors, loop diuretics, intravenous dye, amphotericin B, non-steroidal anti-inflammatory drugs (NSAIDs), the need for vasopressor drugs, and discontinuation of CMS treatment because of AKI were also recorded. The patient's clinical status at the beginning of CMS treatment was defined as infection,

Table 1 Definition of the RIFLE criteria to assess AKI

\begin{tabular}{cc}
\hline Category criteria & Definition \\
\hline Risk (R) & $\begin{array}{c}\text { Increased creatinine level } \times 1.5 \\
\text { or GFR decrease }>25 \%\end{array}$ \\
Injury (I) & $\begin{array}{c}\text { Increased creatinine level } \times 2 \text { or GFR } \\
\text { decrease }>50 \%\end{array}$ \\
Failure (F) & $\begin{array}{c}\text { Increased creatinine level } \times 3, \text { GFR decrease } \\
>75 \%, \text { or creatinine level }>4 \text { mg/dL }\end{array}$ \\
Loss (L) & $\begin{array}{c}\text { Persistent acute renal failure or loss of } \\
\text { function for }>4 \text { weeks }\end{array}$ \\
End-Stage Kidney Disease \\
(ESKD) (E)
\end{tabular}

*GFR, glomerular filtration rate. 
severe sepsis and shock, according to the standard definition [17]. Clinical response was defined as the resolution of signs, symptoms, and laboratory parameters that defined infection for each patient. The 30-day allcause mortality was also recorded.

Evaluation of the colistin concentration in plasma was performed after 3 days of treatment, when the colistin concentrations had reached steady state. The samples were immediately centrifuged (3000 g for 10 minutes) and the plasma was stored at $-80^{\circ} \mathrm{C}$ until analysis. Colistin plasma trough concentrations $\left(\mathrm{C}_{\min }\right)$ were measured just before the next dose. Maximum plasma concentrations $\left(C_{\max }\right)$ were taken 30 minutes after the end of the CMS infusion (1 $\mathrm{h}$ after the start of infusion).

Colistin concentrations in plasma were determined using a validated high-performance liquid chromatography (HPLC) method as described by Li et al. [18], with minor modifications. After protein precipitation, the samples were centrifuged $(14000 \mathrm{~g}, 5 \mathrm{~min})$ and the supernatant transferred to solid phase extraction (SPE) C18 cartridges (Sep-Pak, Waters, Milford, MA, USA), in which derivation with 9-fluorenylmethyl chloroformate (FMOC-Cl) was performed. Elution of the fluorescence derivatives was performed with acetone mixed with acetonitrile and boric acid. Finally, $20 \mu \mathrm{l}$ of the mixture was injected into the HPLC. The HPLC system was made up of Waters equipment that included a Waters 2475 multi- $\lambda$ Fluorescence Detector, a Waters 1525 binary pump with column heater, a Waters degasser, and a Waters 717 autoinjector sampler. The stationary phase was a Waters SunFire column C18, $4.6 \times 15.0 \mathrm{~mm}, 5$ $\mu \mathrm{m}$. The mobile phase was a mixture of acetonitrile, tetrahydrofuran and water delivered at an isocratic flux of $1 \mathrm{~mL} / \mathrm{min}$. The chromatogram run time was $20 \mathrm{mi}-$ nutes and the detector setting was excitation wavelength $260 \mathrm{~nm}$ and emission wavelength $315 \mathrm{~nm}$. The concentrations of colistin were calculated by multiplying the obtained colistin sulfate plasma concentrations by $1163 /$ 1403 (1163 being the average molecular weight of colistin $\mathrm{A}$ and $\mathrm{B}$, which are the greater part of the products, and 1403 the average molecular weight of colistin sulfate). The colistin plasma concentration in each patient was calculated as the sum of colistin A and B, the two main components. Calibration curves were linear in the range $0.1-8 \mathrm{mcg} / \mathrm{ml}$ and the accuracy quality control samples varied from $90-110 \%$ of the nominal concentration for intraday and interday analysis, with a precision $(\mathrm{CV} \%)$ of $10 \%$ or less. The limit of quantification was $0.1 \mathrm{mcg} / \mathrm{ml}$ and the limit of detection was $0.05 \mathrm{mcg} /$ $\mathrm{mL}$.

\section{Statistical analysis}

Dichotomous data were compared using a $\chi^{2}$ or Fisher exact test. Normally distributed continuous data are expressed as means with standard deviations (SD) and were compared using the t-test. Otherwise, values are presented as means with interquartile range (IQR) and were compared using the Mann-Whitney U-test.

Multivariate analysis of risk factors for colistin nephrotoxicity was constructed by using logistic regression. Univariate analyses were performed separately for each of the risk factor variables to ascertain the odds ratio and $95 \%$ confidence interval (CI). All clinically important covariates and those with a $\mathrm{P}$ value $<0.2$ in the univariate analyses were included in the multivariate analysis. Since $C_{\max }$ and $C_{\min }$ values were almost equal, only one of these variables was included in the model. Following Couet et al. [19], $C_{\min }$ was chosen because it is more convenient from a practical viewpoint and because CMS would then be minimal and the risk of colistin concentration overestimation resulting from post-sampling CMS hydrolysis would therefore be considerably reduced.

As we had found a relationship between the development of AKI on day 7 and at the EOT and between colistin levels and 30-day all-cause mortality, a multivariate analysis of risk factors for 30-day all-cause mortality was performed using a logistic regression.

Multivariate logistic regression models were assessed with the Hosmer-Lemeshow goodness-of-fit test and the $\mathrm{C}$-statistic representing the area under the receiver operating characteristics (ROC) curve (AUC).

The ROC curve was used to identify a categorical breakpoint for $\mathrm{C}_{\min }$ that would better identify patients who develop acute kidney injury (AKI) on day 7 and at the end of treatment. For all analyses, a two-sided $P$ value $<0.05$ was considered to be statistically significant. The Statistical Package for the Social Sciences (SPSS, version 15.0) was used for statistical analysis.

\section{Results}

During the study period, colistin was prescribed to 119 patients, 9 of whom did not complete the study protocol, 5 of whom received colistin treatment for less than 72 hours, and 3 of whom were on hemodialysis. The study population included 102 patients. Patient characteristics are summarized in Table 2.

Colistin was administered at 1 million IU three times daily in $28(27.4 \%)$ patients, at 2 million IU three times daily in $42(41.2 \%)$ patients, at 3 million IU three times daily in $16(15.7 \%)$ patients, and at other doses adjusted by renal function in $16(15.7 \%)$ patients. Table 3 shows the characteristics of patients receiving different CMS dosage regimens.

AKI was detected in $53(51.9 \%)$ patients at any time during treatment (26 on day 7 , and 50 at the EOT). Table 4 shows the distribution of AKI on day 7 and at the EOT on the basis of the RIFLE criteria. Fourteen out 
Table 2 Patient characteristics

\begin{tabular}{|c|c|}
\hline & $\begin{array}{l}\text { Included patients } \\
\quad(n=102)\end{array}$ \\
\hline Age, years* & $69(24-91)$ \\
\hline Male sex, n (\%) & $79(77.5)$ \\
\hline APACHE $\|^{* *}$ & $12.4 \pm 5.68$ \\
\hline \multicolumn{2}{|l|}{ Clinical status, n (\%): } \\
\hline - Severe sepsis & $48(47.1)$ \\
\hline - Shock & $8(7.8)$ \\
\hline Intensive Care Unit admission, n (\%) & $24(23.5)$ \\
\hline \multicolumn{2}{|l|}{ Type of infection, n (\%) } \\
\hline - Pneumonia & $24(23.5)$ \\
\hline - Acute bronchitis & $23(22.5)$ \\
\hline - Urinary tract infection & $15(14.7)$ \\
\hline $\begin{array}{l}\text { - Skin and soft tissue infection and surgical } \\
\text { site infection }\end{array}$ & $15(14.7)$ \\
\hline - Bacteremia & $5(4.9)$ \\
\hline - Others & 20 (19.6) \\
\hline \multicolumn{2}{|l|}{ Type of CMS treatment, n (\%) } \\
\hline - Empirical & $3(2.9)$ \\
\hline - Directed: & $99(97.1)$ \\
\hline - Pseudomonas aeruginosa & $89(89.9)$ \\
\hline - Acinetobacter baumannii & $9(9.1)$ \\
\hline - Klebsiella pneumoniae & $1(1)$ \\
\hline${ }^{1} \mathrm{CMS}$ daily dose (millions IU)** & $5.21 \pm 2.24$ \\
\hline${ }^{1} \mathrm{CMS}$ total dose, $(\mathrm{MU})^{* *}$ & $100.54 \pm 92.8$ \\
\hline${ }^{1}$ CMS duration, days ${ }^{* *}$ & $19.57 \pm 15.4$ \\
\hline${ }^{2}$ GFR at baseline $\left(\mathrm{ml} / \mathrm{min} / 1.73 \mathrm{~m}^{2}\right)^{*}$ & $127.9(22.3-560)$ \\
\hline Patients with ${ }^{3} \mathrm{CKD}$ at baseline, $\mathrm{n}(\%)$ & $23(22.5)$ \\
\hline${ }^{4} C_{\min }(\mathrm{mg} / \mathrm{mL})^{*}$ & $1.06(0.11-5.99)$ \\
\hline${ }^{5} \mathrm{C}_{\max }(\mathrm{mg} / \mathrm{mL})^{*}$ & $1.11(0.15-6.62)$ \\
\hline Patients with nephrotoxicity at day $7, \mathrm{n}(\%)$ & $26(25.5)$ \\
\hline - R (Risk) & $16(61.5)$ \\
\hline - I (Injury) & $8(30.7)$ \\
\hline - F (Failure) & $2(7.6)$ \\
\hline $\begin{array}{l}\text { Patients with nephrotoxicity at the end of } \\
\text { treatment, } \mathrm{n}(\%)\end{array}$ & $50(49)$ \\
\hline - R (Risk) & $13(26)$ \\
\hline - I (Injury) & $23(46)$ \\
\hline - F (Failure) & $14(28)$ \\
\hline Clinical response, n (\%) & 79 (77.5) \\
\hline
\end{tabular}

Data are $\mathrm{n}(\%)$ except where indicated.

* Median (interquartile range).

** Mean \pm SD.

${ }^{1} \mathrm{CMS}$ :colistinmethanesulfonate sodium. ${ }^{2} \mathrm{GFR}$ : Glomerular filtration rate. ${ }^{3} \mathrm{CKD}$ : chronic kidney disease. ${ }^{4} \mathrm{C}_{\mathrm{min}}$ : colistin trough plasma concentrations at steady state. ${ }^{5} \mathrm{C}_{\text {max: }}$ colistin maximum plasma concentrations at steady state. of $53(26.4 \%)$ patients who developed AKI during treatment underwent a CMS dose reduction and 3 (5.6\%) had to stop treatment because of AKI. None of the patients who developed AKI needed renal replacement therapy.

Patients had received CMS $10.8 \pm 6.2$ (SD) days when dose adjustment was done. Dose modification was done within the first week in $3(21.4 \%)$ patients and after this time in 11 (78.6\%).

Adjustments of CMS dose were done by prolonging the dosing interval in 7 (50\%) patients, by reducing the single dose in 4 (28.6\%) patients, and by combining both strategies in $3(21.4 \%)$ of patients. CMS dose adjustment at any time was associated with recovery of baseline renal function at the EOT $(\mathrm{P}=0.016)$. However, neither time until dose adjustment nor strategy of dosing modification was related to recovery of baseline renal function at the EOT (data not shown).

At the end of follow up, 33 out of 53 (62.3\%) had recovered their baseline renal function, 16 (30.2\%) died before recovery of renal function, and $4(5.7 \%)$ had no available data. No differences were observed in terms of mean time until recovery of baseline renal function between patients with and without CMS adjustment (10 \pm 10.9 vs $10 \pm 12.5$, respectively; $\mathrm{P}=0.6$ ).

The univariate analyses used to identify risk factors for AKI on day 7 and at EOT are shown in Table 5. Patients with AKI on day 7 were older, had a higher Charlson score, had received higher CMS cumulative doses (from baseline until day 7), and had lower plasma albumin levels. In addition, $C_{\max }$ and $C_{\min }$ were higher than in those without AKI. At the EOT, variables related to AKI were age, Charlson score, CMS cumulative dose and duration of treatment, low plasma albumin levels, concomitant treatment with NSAIDs and loop diuretics, and colistin plasma levels $\left(\mathrm{C}_{\max }\right.$ and $\left.\mathrm{C}_{\min }\right)$. Another finding to consider is the fact that patients with acute renal failure at baseline achieved higher trough and peak colistin plasma levels $(0.86$ [0.11-5.99] vs 1.79 [0.56-5] and 1.00 [0.15-6.62] vs 1.82 [0.52-5]; $\mathrm{P}=0.025$ and $\mathrm{P}=$ 0.017 , respectively). In spite of this, the presence of acute renal failure was not related to the development of AKI either on day 7 or at the EOT.

Variables with a $\mathrm{p}$ value $\leq 0.20$ were introduced in a multivariate logistic regression model. For day $7, \mathrm{C}_{\mathrm{min}}$ (odds ratio [OR] 4.7; 95\% confidence interval [CI] 2.389.29) was the only predictor of renal dysfunction. For EOT, Charlson score (OR 1.3; 95\% CI 1.015-1.572), $\mathrm{C}_{\text {min }}$ (OR 2.1; 95\% CI 1.33-3.42), and co administration of $\geq 2$ nephrotoxic drugs (OR 2.61; CI 95\% 1.0-6.7) were identified as risk factors for AKI (Table 6). The final model showed a very good overall discriminatory power for AKI with an AUC value of 0.898 (95\% CI $0.82-0.97, \mathrm{P}<0.001$ ) on day 7 and 0.772 (95\% CI $0.68-$ $0.86, P<0.001)$ at the EOT. 
Table 3 Clinical and demographic characteristics of patients receiving different CMS dosage regimens

\begin{tabular}{|c|c|c|c|c|c|}
\hline \multirow[t]{2}{*}{ Variable } & \multicolumn{4}{|c|}{ Colistin dosage regimen, $\mathrm{n}(\%)$} & \multirow[t]{2}{*}{$P$} \\
\hline & $\begin{array}{c}1 \text { million IU/8 h } \\
(n=28)\end{array}$ & $\begin{array}{c}2 \text { million IU/8 h } \\
(n=42)\end{array}$ & $\begin{array}{c}3 \text { million IU/8 h } \\
(n=16)\end{array}$ & $\begin{array}{l}\text { Other doses } \\
(n=16)\end{array}$ & \\
\hline Age (yrs) & $74(24-85)$ & $67(27-91)$ & $55.5(28-74)$ & $73(42-85)$ & 0.023 \\
\hline № (\%) of male patients & $22(78.6)$ & $32(76.2)$ & $14(87.5)$ & $11(68.8)$ & 0.64 \\
\hline Charlson score & $4.8 \pm 2.8$ & $4.36 \pm 2.6$ & $3.7 \pm 2.5$ & $4.8 \pm 2.1$ & 0.41 \\
\hline № (\%) of severe sepsis & $11(39.3)$ & $22(52.4)$ & $9(56.3)$ & $6(37.5)$ & 0.5 \\
\hline No (\%) septic shock & $1(3.6)$ & $3(7.1)$ & $2(12.5)$ & $2(12.5)$ & 0.63 \\
\hline APACHE ॥ & $12.8 \pm 6.7$ & $11.9 \pm 4.6$ & $11.5 \pm 4.45$ & $13.7 \pm 7.5$ & 0.28 \\
\hline${ }^{1} \mathrm{CKD}$ at baseline & $12(42.9)$ & $7(16.7)$ & $1(6.3)$ & $11(68.8)$ & $<0.0001$ \\
\hline Colistin dose (in ${ }^{2} \mathrm{CBA}$ ) in mg/kg/day ( ${ }^{3} \mathrm{IBW}$ ) & $1.48 \pm 0.3$ & $2.9 \pm 0.37$ & $4.38 \pm 0.9$ & $1.54 \pm 0.82$ & $<0.0001$ \\
\hline${ }^{4} \mathrm{Cmin}$ & $0.71(0.2-2.01)$ & $1.14(0.11-5)$ & $1.84(0.45-5.99)$ & $1.5(0.16-3.02)$ & 0.003 \\
\hline${ }^{5} \mathrm{Cmax}$ & $0.65(0.24-1.99)$ & $1.13(0.15-5)$ & $1.84(0.5-6.62)$ & $1.5(0.16-3.7)$ & 0.001 \\
\hline${ }^{6} \mathrm{CMS}$ cumulative dose & $58.5 \pm 50.6$ & $111.7 \pm 85.9$ & $171.5 \pm 105.7$ & $73.9 \pm 111.3$ & $<0.0001$ \\
\hline CMS duration treatment & $20 \pm 16.5$ & $19.5 \pm 15.6$ & $19.25 \pm 8$ & $19.2 \pm 19.8$ & 0.41 \\
\hline Concomitant antibiotics & $15(53.6)$ & $23(54.8)$ & $10(62.5)$ & $8(50)$ & 0.9 \\
\hline${ }^{7} \mathrm{AKI}$ at day 7 & $5(17.9)$ & $11(26.2)$ & $7(43.8)$ & $3(18.8)$ & 0.25 \\
\hline AKI at ${ }^{8} \mathrm{EOT}$ & $14(50)$ & $21(50)$ & $9(56.3)$ & $6(37.5)$ & 0.7 \\
\hline Clinical response & $25(89.3)$ & $32(76.2)$ & $11(68.8)$ & $11(68.8)$ & 0.3 \\
\hline
\end{tabular}

Data are $\mathrm{n}(\%)$ except where indicated.

* Median (interquartile range).

** Mean \pm SD.

${ }^{1} \mathrm{CKD}$ : chronic kidney disease. ${ }^{2} \mathrm{CBA}$ : colistin base activity. ${ }^{3} \mathrm{IBW}$ : ideal body weight. ${ }^{4} \mathrm{C}_{\text {min }}$ : colistin trough plasma concentrations at steady state. ${ }^{5} \mathrm{C}_{\max }$ colistin maximum plasma concentrations at steady state. ${ }^{6} \mathrm{CMS}$ : colistinmethanesulfonate sodium ${ }^{7} \mathrm{AKI}$ : acute kidney injury. ${ }^{8} \mathrm{EOT}$ : end of treatment.

When $C_{\min }$ was evaluated as a categorical variable, based on the ROC curve, the breakpoints that best predicted AKI at day 7 and at the EOT were $3.33 \mathrm{mg} / \mathrm{L}$ and $2.42 \mathrm{mg} / \mathrm{L}$ with a sensitivity of 0.46 and 0.42 and specificity of 1.00 and 0.96 , respectively $(\mathrm{P}<0.001)$. The positive predictive values and the negative predictive values were $100 \%$ and $87.5 \%$ and $84.4 \%$ and $62.8 \%$, respectively.

$\mathrm{C}_{\min }$ was also evaluated by defining four groups on the basis of quartiles as shown in Table 7. Both AKI on day 7 and at the EOT were related to $\mathrm{C}_{\min }(\mathrm{p}<0.001)$.

The 30 -day all-cause mortality rate was $32.4 \%$. Another important finding is that in the univariate analysis the development of AKI on day 7 and at the EOT were both

Table 4 patient relationship to the RIFLE criteria on day 7 and at the EOT

\begin{tabular}{lcc}
\hline Criterion & \multicolumn{2}{c}{$\mathbf{N}^{\circ}(\mathbf{\%})$ of patients fulfilling criterion } \\
\cline { 2 - 3 } & Day $\mathbf{7}(\mathbf{n}=\mathbf{1 0 2})$ & EOT $(\mathbf{n}=\mathbf{1 0 2})$ \\
\hline No injury & $76(74.5)$ & $52(51)$ \\
Risk (R) & $16(15.7)$ & $14(13.7)$ \\
Injury (I) & $8(7.8)$ & $23(22.5)$ \\
Failure (F) & $2(2)$ & $13(12.7)$ \\
Loss (L) & $0(0)$ & $0(0)$ \\
ESKD (E) & $0(0)$ & $0(0)$ \\
\hline
\end{tabular}

related to 30-day all-cause mortality $(\mathrm{p}=0.031$ and $\mathrm{p}=$ 0.006, respectively). Furthermore, higher $C_{\min }$ values were also related to 30-day mortality $(\mathrm{p}=0.010)$ (data not shown). However in the multivariate analysis the only factors related to 30-day all-cause mortality were AKI at the EOT (OR 4.01; 95\% CI 1.57-10.23; $\mathrm{P}=0.004$ ) and APACHE score (OR 1.11; 95\% CI 1.09-1.21; P = 0.008).

\section{Discussion}

The aim of this study was to determine the incidence of colistin-associated nephrotoxicity and evaluate the colistin plasma concentrations as a predictor of AKI in patients treated with this antimicrobial agent. Using the RIFLE criteria to assess the incidence of AKI related to CMS treatment on day 7 and at the EOT, nephrotoxicity was observed in $25 \%$ and $49 \%$ patients respectively.

The reported rate of colistin-associated nephrotoxicity varies from $0 \%$ to $37 \%$ in older studies $[2,3,20,21]$. This variability could be the result of differences in the definitions of nephrotoxicity and in the dose and duration of treatment with CMS in earlier studies. In the present study, the rates of AKI at EOT (49\%) are slightly higher than those reported in recent studies that used the RIFLE criteria $(43-45 \%)[8,9]$.

The association between increased colistin dose and improved outcome has been previously reported by 
Table 5 Clinical and demographic characteristics of patients with and without nephrotoxicity

\begin{tabular}{|c|c|c|c|c|c|c|}
\hline & $\begin{array}{l}\text { Patients without } \\
\text { nephrotoxicity } \\
(n=76)\end{array}$ & $\begin{array}{l}\text { Patients with } \\
\text { nephrotoxicity } \\
(n=26)\end{array}$ & $\mathbf{P}$ & $\begin{array}{l}\text { Patients without } \\
\text { nephrotoxicity } \\
(\mathrm{n}=52)\end{array}$ & $\begin{array}{l}\text { Patients with } \\
\text { nephrotoxicity } \\
(n=50)\end{array}$ & $\mathbf{P}$ \\
\hline & \multicolumn{2}{|c|}{ Day 7} & \multicolumn{4}{|c|}{ EOT } \\
\hline Age, years* & $66.5(24-91)$ & $73(41-84)$ & 0.036 & $65(24-91)$ & $72.5(30-87)$ & 0.016 \\
\hline Male sex & $61(80.3)$ & $18(69.2)$ & 0.281 & $40(76.9)$ & $39(49.4)$ & 1 \\
\hline Charlson Index* & $4.12 \pm 2.58$ & $5.5 \pm 2.34$ & 0.031 & $3.6 \pm 2.4$ & $5.36 \pm 2.3$ & 0.001 \\
\hline APACHE $\|$ & $14.9 \pm 6.4$ & $14.8 \pm 7$ & 0,32 & $15.3 \pm 6$ & $14.2 \pm 7$ & 0,16 \\
\hline \multicolumn{7}{|l|}{ Clinical status: } \\
\hline - Severe sepsis & 39 (51.3) & $9(34.6)$ & 0.175 & $24(46.2)$ & $24(48)$ & 1 \\
\hline - Shock & $7(9.2)$ & $1(3.8)$ & 0.457 & $7(13.5)$ & $1(2)$ & 0.06 \\
\hline Acute renal failure at baseline & $11(14.5)$ & $4(15.4)$ & 1 & $4(7.7)$ & $11(22)$ & 0.052 \\
\hline${ }^{1}$ CKD at baseline & $17(22.3)$ & $6(23)$ & 1 & $11(21.15)$ & $12(24)$ & 0.81 \\
\hline Albumin* & $2.8 \pm 0.62$ & $2.5 \pm 0.62$ & 0.047 & $2.8 \pm 0.62$ & $2.6 \pm 0.62$ & 0.031 \\
\hline${ }^{1} \mathrm{BMI}\left(\mathrm{Kg} / \mathrm{m}^{2}\right)^{*}$ & $25.6 \pm 5.9$ & $24.3 \pm 5.03$ & 0.26 & $25.2 \pm 5$ & $25.4 \pm 6.35$ & 0.75 \\
\hline${ }^{3} \mathrm{CMS}$ total dose $(\mathrm{MU})^{*}$ & $35.1 \pm 15.15$ & $42 \pm 15.84$ & 0.06 & $97.3 \pm 106.35$ & $103.9 \pm 78.5$ & 0.047 \\
\hline Duration of CMS treatment, days* & & & & $18.7 \pm 16.6$ & $21.02 \pm 14.42$ & 0.047 \\
\hline${ }^{4} C_{\min }, \mathrm{mg} / \mathrm{mL}^{*}$ & $0.78(0.11-3.2)$ & $3.11(0.45-5.99)$ & $<0.0001$ & $0.7(0.11-5.7)$ & $1.18(0.16-5.99)$ & $<0.0001$ \\
\hline${ }^{5} \mathrm{C}_{\max }, \mathrm{mg} / \mathrm{mL}^{*}$ & $0.78(0.15-3)$ & $3.2(0.68-6.62)$ & $<0.0001$ & $0.74(0.15-6.10)$ & $1.81(0.16-6.62)$ & $<0.0001$ \\
\hline Concomitant aminoglycoside use & $24(31.6)$ & $8(30.8)$ & 1 & $16(30.8)$ & $16(32)$ & 1 \\
\hline Concomitant vancomycin use & $8(10.5)$ & $1(3.8)$ & 0.442 & $3(5.8)$ & $6(12)$ & 0.314 \\
\hline Concomitant ${ }^{6} \mathrm{NSAID}$ use & $11(14.5)$ & $4(15.4)$ & 1 & $3(5.8)$ & $12(24)$ & 0.012 \\
\hline Concomitant loop diuretic use & $31(40.8)$ & $15(57.7)$ & 0.172 & $16(30.8)$ & $30(60)$ & 0.005 \\
\hline Other concomitant nephrotoxic drugs & $17(22.4)$ & $4(14.4)$ & 0.579 & $13(25)$ & $8(16)$ & 0.33 \\
\hline$\geq 2$ nephrotoxic drugs & 37 (48.7) & $13(50)$ & 1 & $20(38.5)$ & $30(60)$ & 0.047 \\
\hline
\end{tabular}

Data are $\mathrm{n}(\%)$ except where indicated.

* Median (interquartile range).

** Mean \pm SD.

${ }^{1} \mathrm{CKD}$ : chronic kidney disease. ${ }^{2} \mathrm{BMI}$ : body mass index. ${ }^{3} \mathrm{CMS}$ :colistinmethanesulfonate sodium. ${ }^{4} \mathrm{C}_{\min }$ : colistin trough plasma concentrations at steady state. ${ }^{5} \mathrm{C}_{\mathrm{mqx}}$ : colistin maximum plasma concentrations at steady state. ${ }^{6}$ NSAID: non-steroidal anti-inflammatory drugs.

some authors $[12,22]$. In addition, recent PK and PD studies have revealed a need for higher doses of colistin to maximize efficacy $[23,24]$. By contrast, in this study, higher doses of colistin were not related to a better clinical outcome. However, clinical response rate was similar to those reported by other authors [2,25-28]. These results could be explained in part by the fact that only 16 patients had received higher CMS doses ( 3 million IU every 8 hours).

The finding that $\mathrm{C}_{\min }$ and $\mathrm{C}_{\max }$ values were practically identical once the steady state was reached, has been previously observed by other authors [24]. In this scenario Couet et al. recommend not to try to differentiate between peak and trough concentrations [19] and for the purposes of drug monitoring, they say it would be more advisable to sample immediately before CMS dosing because CMS concentrations would then be minimal and the risk of colistin concentration overestimation resulting from post-sampling CMS hydrolysis would therefore be considerably reduced.
The most important finding of our study is that $\mathrm{C}_{\min }$ is a stronger predictor of AKI both on day 7 and at EOT. In previous reports, some authors have demonstrated that colistin nephrotoxicity is related to the cumulative dose and the duration of CMS therapy $[7,9,11,26,27]$. In the current study, the duration of therapy and the cumulative CMS dose showed a trend towards statistical significance in the univariate analysis that disappeared after adjusting for other variables. In addition, daily colistin dose calculated by analyzing the amount of colistin base activity (CBA) per ideal body weight (data not shown) was not related to AKI. These results are consistent with those of Falagas et al. [28,29] but in disagreement with Pogue et al. [8], who have recently shown that renal insufficiency occurred in a dose-dependent manner.

The association between higher doses of CMS and higher colistin plasma concentrations suggest that this polymyxin has linear pharmacokinetics. However, while colistin levels were the strongest predictor of AKI, no 
Table 6 Multivariate analysis for independent risk factors for colistin-associated nephrotoxicity at day 7 and at the EOT

\begin{tabular}{|c|c|c|}
\hline \multicolumn{3}{|c|}{ Day 7} \\
\hline Variable & $\begin{array}{c}\text { Odds ratio } \\
(95 \% \mathrm{Cl})\end{array}$ & $\mathbf{P}$ \\
\hline Age & $1.01(0.95-1.08)$ & 0.75 \\
\hline Charlson score & $1.04(0.71-1.52)$ & 0.84 \\
\hline Albumin & $0.89(0.33-2.42)$ & 0.83 \\
\hline${ }^{1} \mathrm{CMS}$ cumulative dose at day 7 & $0.99(0.94-1.04)$ & 0.73 \\
\hline${ }^{2} C_{\min }$ & $4.7(2.38-9.29)$ & $<0.001$ \\
\hline \multicolumn{3}{|c|}{ End of treatment } \\
\hline Variable & $\begin{array}{c}\text { Odds ratio } \\
(95 \% \mathrm{Cl})\end{array}$ & $\mathbf{P}$ \\
\hline Age & $0.98(0.93-1.03)$ & 0.51 \\
\hline Charlson score & $1.3(1.01-1.57)$ & 0.036 \\
\hline Albumin & $0.59(0.25-1.38)$ & 0.22 \\
\hline CMS cumulative dose & $0.99(0.98-1)$ & 0.38 \\
\hline CMS duration treatment & $1.03(0.98-1.08)$ & 0.24 \\
\hline$C_{\min }$ & $2.1(1.33-3.42)$ & 0.002 \\
\hline${ }^{3}$ NSAID use & $5.09(0.9-28.54)$ & 0.64 \\
\hline Loop diuretic use & $1.97(0.61-6.38)$ & 0.25 \\
\hline $\begin{array}{l}\text { Co-administration of } \\
>2 \text { nephrotoxic drugs }\end{array}$ & $2.61(1-6.7)$ & 0.049 \\
\hline
\end{tabular}

${ }^{1} \mathrm{CMS}$ :colistinmethanesulfonate sodium. ${ }^{2} \mathrm{C}_{\text {min }}$ : colistin trough plasma concentrations at steady state. ${ }^{3} \mathrm{NSAID}$ : non-steroidal anti-inflammatory drugs.

relationship was found between AKI and daily colistin dose nor cumulative colistin dose. This could be because the average colistin steady-state plasma concentrations (both $\mathrm{C}_{\max }$ and $\mathrm{C}_{\min }$ ) varied in a relatively wide range, reflecting great inter-patient variability. In a population pharmacokinetic study, Garonzik et al. [23] observed a strong inverse trend between colistin steady-state plasma concentrations $\left(\mathrm{C}_{\mathrm{ss}}\right.$, avg $)$ and creatinine clearance, suggesting that in patients with normal or moderately impaired renal function, the currently recommended daily doses of CMS are not sufficient to obtain efficacious steady-state concentrations of colistin, and proposed a maintenance dose equation for optimizing colistin efficacy. However, according to Pogue et al. [8], the proposed doses

Table 7 Incidence of AKI on day 7 and at the EOT related to quartiles of $C_{\min }$ values at steady state

\begin{tabular}{lcccc}
\hline & \multicolumn{4}{c}{ Cmin (mg/dL) } \\
\cline { 2 - 5 } & $\leq \mathbf{0 . 5 6}$ & $\mathbf{0 . 5 7 - 1 . 0 4}$ & $\mathbf{1 . 0 5}-\mathbf{2 . 2}$ & $>\mathbf{2 . 2}$ \\
\hline Nephrotoxicity on day 7 & $1(4)$ & $0(0)$ & $8(32)$ & $17(65.4)$ \\
\hline & \multicolumn{4}{c}{$\mathbf{C m i n}$ (mg/dL) } \\
\cline { 2 - 5 } & $\leq \mathbf{0 . 5 6}$ & $\mathbf{0 . 5 7 - 1 . 0 4}$ & $\mathbf{1 . 0 5 - 2 . 2}$ & $>\mathbf{2 . 2}$ \\
\hline Nephrotoxicity at the EOT & $5(20)$ & $10(38.5)$ & $13(52)$ & $22(84.6)$ \\
\hline Data are $\mathrm{n}$ (\%) of patients in each concentration category.
\end{tabular}

would significantly increase risk of AKI. In this scenario, another group [19] have analyzed the effect of altered CMS renal clearance on $\mathrm{C}_{\mathrm{ss} \text {, avg }}$ and have concluded that moderate renal impairment should not only be viewed as a risk factor for toxicity due to overexposure, but also as an opportunity to reach efficient colistin concentrations. This relationship between creatinine clearance and colistin plasma levels was also observed in our study, as patients who had developed acute renal failure at baseline achieved higher colistin plasma levels at steady state.

Regarding colistin plasma levels, another factor to consider is that impaired enzymatic activity caused by liver disease or drug-drug interactions could perhaps be responsible for reduced colistin clearance and, in turn, high average steady-state concentrations [19]. Unfortunately, all these data suggest that colistin clearance impairment in a particular individual is almost impossible to predict and that therefore colistin concentration monitoring could help physicians to adapt CMS dosing regimens.

Another point of the study that needs to be underlined is the fact that the co-administration of $\geq 2$ nephrotoxins during CMS treatment was associated with AKI at EOT. This fact could be explained by the additive effect of nephrotoxic drugs during treatment. Although some recent reports suggest an association between vancomycin and nephrotoxicity [30], in this study vancomycin was not a risk factor for AKI. Furthermore, in line with Pogue et al. [8], aminoglycosides were not related to nephrotoxicity. These results could be influenced by the limited sample size. In any case, it would be advisable for physicians always to consider the potential synergistic effect between colistin and other nephrotoxic drugs.

Regarding the relationship between the development of AKI at the EOT and all cause 30-day mortality, other authors have demonstrated that AKI itself is associated with higher mortality $[6,30]$.

In conclusion, these results emphasize that colistin is a drug with a narrow therapeutic range because the findings of possible better outcomes with optimized colistin dosing should be tempered with the equal possibility of worsening renal function associated with higher colistin plasma levels. In line with this and also with Dalfino et al. [26,27], our results suggest that the administration of higher daily CMS doses while prolonging the dosing interval (according to colistin's concentration-dependent pharmacokinetic behavior) could be a reasonable strategy to maximize efficacy without increasing the risk of nephrotoxicity.

Our study has some limitations. Despite the prospective design, the lack of a control group represents a major limitation. We were not able to assess the potential relationship between values of the area under the colistin concentration versus time curves over $24 \mathrm{~h}\left(\mathrm{AUC}_{0-24}\right)$ and AKI, mainly because of the difficulty of taking 
several samples from patients that were not in the ICU. CMS plasma concentrations were not determined. CMS is mainly cleared renally and for this reason creatinine clearance reductions may produce CMS accumulation [23]. Consequently, a larger proportion of CMS is converted to colistin, and brings about an increase of the colistin plasma levels in patients with creatinine clearance reductions. The possible association between CMS concentrations and AKI should be assessed in further studies. Finally, the severity of disease at the time of the first CMS dose was stratified in all included patients according to the Acute Physiology and the Chronic Health Evaluation (APACHE) II, despite the fact that this score has only been validated in ICU patients.

\section{Conclusions}

To our knowledge, the present study is the first to demonstrate that $\mathrm{C}_{\min }$ is an independent risk factor for colistin-associated AKI. In fact, $\mathrm{C}_{\min }$ was identified as the only predictor for AKI after a week of CMS treatment and also a potent risk factor for renal toxicity at the EOT. Consequently, monitoring plasma concentrations of colistin may be a useful strategy for the prediction and prevention of AKI in patients undergoing CMS therapy.

This study also raises new challenges. According to the observations by other authors $[24,31]$ and in the present study, even at steady state, plasma concentrations were below MIC breakpoints for most of the MDR-GNB causing infections. This shows that further investigations are needed to define the optimal colistin plasma concentrations and, consequently, the optimum-dosing regimen. In this scenario, the study results suggest that physicians should be cautious about using colistin and that monitoring colistin plasma concentrations is valuable for preventing colistinassociated nephrotoxicity.

\begin{abstract}
Abbreviations
CMS: Colistin methanesulfonate sodium; $C_{\text {min: }}$ : Colistin trough levels; $C_{\text {max }}$ : Colistin peak levels; EOT: End of treatment; AKI: Acute kidney injury; MDR-GNB: Multidrug resistant gram-negative bacteria; NSAID: Antiinflammatory drugs; IU: International units; GFR: Glomerular filtration rate; MDRD-4: Abbreviated modification of diet in the renal disease equation; APACHE II score: Acute physiology and the chronic health evaluation score; HPLC: High-performance liquid chromatography; SPE: Solid phase extraction; FMOC-Cl: 9-fluorenylmethyl chloroformate; ROC curves: Receiver operating characteristics curves; AUC: Area under the curve; $\mathrm{C}_{\mathrm{ss}, \text { avg }}$ : Colistin steady state average concentration; $\mathrm{AUC}_{0-24}$ : Concentration vs time curves over $24 \mathrm{~h}$.
\end{abstract}

\section{Competing interests}

Financial support. This work was supported by grants from Instituto de Salud Carlos III (FIS) FEDER, PS09/01634.

The authors declare that they have no competing interests.

\section{Authors' contributions}

LS: conceived the study, patient selection, data collection and analysis, and wrote the manuscript. SL: validated HPLC analytical method, management and analysis of clinical specimens, patient selection and data analysis. SG: participated in the design of the study and helped to draft the manuscript. NB: patient selection and management and analysis of clinical specimens. CS: microbiological assessment. MM: data collection. FAL: made substantial contributions to interpretation of data and helped to adjust the antibiotic therapy in ICU patients. HK: helped to draft the manuscript. NB: made substantial contributions to interpretation of data and helped to draft the manuscript. JPH: participated in the design of the study, made substantial contributions to interpretation of data and helped to draft the manuscript. All authors read the manuscript and approved the final version.

\section{Author details}

${ }^{1}$ Infectious Diseases Service, Parc de Salut Mar, Passeig Marítim 25-29, E-08003 Barcelona, Spain. ${ }^{2}$ Pharmacy Service, Parc de Salut Mar, Passeig Marítim 25-29, E-08003 Barcelona, Spain. ${ }^{3}$ Intensive Care Medicine Service, Parc de Salut Mar, Passeig Marítim 25-29, E-08003 Barcelona, Spain.

${ }^{4}$ Laboratori de Referència de Catalunya, C/ de la Selva 10, E-08820 Barcelona, Spain. ${ }^{5}$ Unit of Infectious Diseases. Department of Internal Medicine, Hospital de la Santa Creu i Sant Pau - Institut d'Investigació Biomèdica Sant Pau. Universitat Autònoma de Barcelona, Sant Quintí 89, 08025 Barcelona, Spain. ${ }^{6}$ Spanish Network for Research in Infectious Diseases (REIPI), Seville, Spain.

Received: 17 October 2012 Accepted: 12 August 2013

Published: 19 August 2013

\section{References}

1. Falagas ME, Rafailidis PI, Kasiakou SK, Hatzopoulou P, Michalopoulos A: Effectiveness and nephrotoxicity of colistin monotherapy vs. colistinmeropenem combination therapy for multidrug-resistant gram-negative bacterial infections. Clin Microbiol Infect 2006, 12:1227-1230.

2. Montero M, Horcajada JP, Sorli L, Alvarez-Lerma F, Grau S, Riu M, et al: Effectiveness and safety of colistin for the treatment of multidrugresistant pseudomonas aeruginosa infections. Infection 2009, 37:461-465.

3. Ouderkirk JP, Nord JA, Turett GS, Kislak JW: Polymyxin B nephrotoxicity and efficacy against nosocomial infections caused by multiresistant gram-negative bacteria. Antimicrob Agents Chemother 2003, 47:2659-2662

4. Yahav D, Farbman L, Leibovici L, Paul M: Colistin: New lessons on an old antibiotic. Clin Microbiol Infect 2012, 18:18-29.

5. Garnacho-Montero J, Amaya-Villar R: Multiresistant acinetobacter baumannii infections: epidemiology and management. Curr Opin Infect Dis 2010, 23:332-339.

6. Ko H, Jeon $M$, Choo E, Lee E, Kim $T$, Jun JB, et al: Early acute kidney injury is a risk factor that predicts mortality in patients treated with colistin. Nephron Clin Pract 2011, 117:c284-c288.

7. Rattanaumpawan $P$, Ung rasert $P$, Thamlikitkul V: Risk factors for colistinassociated nephrotoxicity. J Infect 2011, 62:187-190.

8. Pogue JM, Lee J, Marchaim D, Yee V, Zhao JJ, Chopra T, et al: Incidence of and risk factors for colistin-associated nephrotoxicity in a large academic health system. Clin Infect Dis 2011, 53:879-884.

9. Hartzell JD, Neff R, Ake J, Howard R, Olson S, Paolino K, et al: Nephrotoxicity associated with intravenous colistin (colistimethate sodium) treatment at a tertiary care medical center. Clin Infect Dis 2009, 48:1724-1728.

10. Falagas ME, Fragoulis KN, Kasiakou SK, Sermaidis GJ, Michalopoulos A: Nephrotoxicity of intravenous colistin: a prospective evaluation. Int J Antimicrob Agents 2005, 26:504-507.

11. Deryke CA, Crawford AJ, Uddin N, Wallace MR: Colistin dosing and nephrotoxicity in a large community teaching hospital. Antimicrob Agents Chemother 2010, 54:4503-4505.

12. Falagas ME, Rafailidis PI, loannidou E, Alexiou VG, Matthaiou DK, Karageorgopoulos DE, et al: Colistin therapy for microbiologically documented multidrug-resistant gram-negative bacterial infections: a retrospective cohort study of 258 patients. Int J Antimicrob Agents 2010, 35:194-199.

13. National Kidney Foundation: K/DOQI clinical practice guidelines for chronic kidney disease: evaluation, classification, and stratification. Am J Kidney Dis 2002, 39(2 Suppl 1):1-266.

14. Bellomo R, Ronco C, Kellum JA, Mehta RL, Palevsky P, Acute Dialysis Quality Initiative workgroup: Acute renal failure - definition, outcome measures, animal models, fluid therapy and information technology needs: The second international consensus conference of the acute dialysis quality initiative (ADQI) group. Crit Care 2004, 8:R204-R212.

15. Charlson M, Szatrowski TP, Peterson J, Gold J: Validation of a combined comorbidity index. J Clin Epidemiol 1994, 47:1245-1251. 
16. Knaus WA, Draper EA, Wagner DP, Zimmerman JE: APACHE II: a severity of disease classification system. Crit Care Med 1995, 13:818-829.

17. American college of chest Physicians/Society of critical care medicine consensus conference: Definitions for sepsis and organ failure and guidelines for the use of innovative therapies in sepsis. Crit Care Med 1992, 20:864-874.

18. Li J, Milne RW, Nation RL, Turnidge JD, Coulthard K, Johnson DW: A simple method for the assay of colistin in human plasma, using pre-column derivatization with 9-fluorenylmethyl chloroformate in solid-phase extraction cartridges and reversed-phase high-performance liquid chromatography. J Chromatogr B Biomed Sci Appl 2001, 25:167-175.

19. Couet W, Gregoire N, Marchand S, Mimoz O: Colistin pharmacokinetics: the fog is lifting. Clin Microbiol Infect 2012, 18:30-39.

20. Falagas ME, Kasiakou SK: Toxicity of polymyxins: a systematic review of the evidence from old and recent studies. Crit Care 2006, 10:R27.

21. Falagas ME, Kasiakou SK, Tsiodras S, Michalopoulos A: The use of intravenous and aerosolized polymyxins for the treatment of infections in critically ill patients: a review of the recent literature. Clin Med Res 2006, 4:138-146.

22. Vicari G, Bauer SR, Neuner EA, Lam SW: Association between colistin dose and microbiologic aoutomes in patients with multidrug-resistant gramnegative bacteremia. Clin Infect Dis 2013, 56:398-404.

23. Garonzik SM, Li J, Thamlikitkul V, Paterson DL, Shoham S, Jacob J, et al: Population pharmacokinetics of colistin methanesulfonate and formed colistin in critically ill patients from a multicenter study provide dosing suggestions for various categories of patients. Antimicrob Agents Chemother 2011, 55:3284-3294.

24. Plachouras D, Karvanen M, Friberg LE, Papadomichelakis E, Antoniadou A, Tsangaris I, et al: Population pharmacokinetic analysis of colistin methanesulfonate and colistin after intravenous administration in critically ill patients with infections caused by gram-negative bacteria. Antimicrob Agents Chemother 2009, 53:3430-3436.

25. Michalopoulos AS, Tsiodras S, Rellos K, Mentzelopoulos S, Falagas ME: Colistin treatment in patients with ICU-acquired infections caused by multiresistant gram-negative bacteria: the renaissance of an old antibiotic. Clin Microbiol Infect 2005, 11:115-121.

26. Dalfino L, Puntillo F, Mosca A, Monno R, Spada ML, Coppolecchia S, et al: High-dose, extended-interval colistin administration in critically ill patients: Is this the right dosing strategy? A preliminary study. Clin Infect Dis 2012, 54:1720-1726

27. Falagas ME, Kasiakou SK, Kofteridis DP, Roditakis G, Samonis G: Effectiveness and nephrotoxicity of intravenous colistin for treatment of patients with infections due to polymyxin-only-susceptible (POS) gram-negative bacteria. Eur J Clin Microbiol Infect Dis 2006, 25:596-9.

28. Falagas ME, Rizos M, Bliziotis IA, Rellos K, Kasiakou SK, Michalopoulos A Toxicity after prolonged (more than four weeks) administration of intravenous colistin. BMC Infect Dis 2005, 10(5):1.

29. Lodise TP, Lomaestro B, Graves J, Drusano GL: Larger vancomycin doses (at least four grams per day) are associated with an increased incidence of nephrotoxicity. Antimicrob Agents Chemother 2008, 52:1330-1336.

30. Ricci Z, Cruz D, Ronco C: The RIFLE criteria and mortality in acute kidney injury: a systematic review. Kidney Int 2008, 73:538-546.

31. Markou N, Markantonis SL, Dimitrakis E, Panidis D, Boutzouka E, Karatzas S, et al: Colistin serum concentrations after intravenous administration in critically ill patients with serious multidrug-resistant, gram-negative bacilli infections: A prospective, open-label, uncontrolled study Clin Ther 2008, 30:143-151.

doi:10.1186/1471-2334-13-380

Cite this article as: Sorli et al: Trough colistin plasma level is an independent risk factor for nephrotoxicity: a prospective observational cohort study. BMC Infectious Diseases 2013 13:380.

\section{Submit your next manuscript to BioMed Central and take full advantage of:}

- Convenient online submission

- Thorough peer review

- No space constraints or color figure charges

- Immediate publication on acceptance

- Inclusion in PubMed, CAS, Scopus and Google Scholar

- Research which is freely available for redistribution

Submit your manuscript at www.biomedcentral.com/submit
C Biomed Central 